\title{
Rash in a returned traveller from Bali
}

Wayne Liao, Naomi Runnegar

\section{CASE}

An otherwise healthy man aged 31 years presented after returning two weeks earlier from a 10-day holiday in Bali, Indonesia. Five days ago he developed subjective fevers, generalised arthralgia, fatigue, vomiting, diarrhoea and a headache. He also had a few days of retro-orbital pain, which resolved prior to his appointment with the general practitioner. On the day of his appointment, he noticed a rash covering his torso and limbs. He did not receive any vaccinations or malaria prophylaxis prior to travel. There was no sexual contact or intravenous drug use during his holiday.

On examination he was afebrile and there were no remarkable findings except the reported rash (Figure 1). Urgent investigations showed normal haemoglobin and haematocrit; mild neutropenia $\left(2.8 \times 10^{9}\right.$ cells $\left./ \mathrm{L}\right)$, lymphopenia $\left(0.96 \times 10^{9}\right.$ cells $\left./ \mathrm{L}\right)$ and thrombocytopenia $\left(121 \times 10^{9}\right.$ cells $\left./ \mathrm{L}\right)$; mild transaminases derangement and an elevated C-reactive protein of $13 \mathrm{mg} / \mathrm{L}$.

\section{QUESTION 1}

Besides dengue, what differentials need to be considered in a returned traveller from South-East Asia?

\section{QUESTION 2}

What is the epidemiology of dengue in Australia?

\begin{abstract}
ANSWER 1
Dengue is the most common cause of fever in returned travellers from South-East Asia. ${ }^{1}$ Other causes of fever accompanied by rash include chikungunya, zika, rickettsial infections, measles, acute human immunodeficiency virus infection and enteric fever. ${ }^{2}$ Malaria needs to be excluded in patients who are febrile. Viral hepatitis, influenza, infectious mononucleosis and locally acquired Ross River virus and Barmah Forest virus are also important differentials.
\end{abstract}

\section{ANSWER 2}

Dengue virus is not endemic in Australia. ${ }^{3}$ Imported cases are reported in all states and territories. ${ }^{4}$ The primary mosquito vector Aedes aegypti is limited to northern Queensland, where yearly outbreaks occur because of vector spread from imported index cases. ${ }^{3}$ There were 1030 confirmed cases in $2017 .^{5}$

Travel to Indonesia is associated with the highest risk when compared with all other destinations, with peak acquisition occurring between December and April. ${ }^{4,6}$

\section{CASE CONTINUED}

The patient's initial serology results were:

- dengue non-structural protein 1 (NS1) antigen: positive

- dengue groups 1-4 immunoglobulin (Ig) M: positive

- dengue groups 1-4 IgG: negative.

Chikungunya alphavirus IgM was positive but failed to demonstrate a rise in IgG over two weeks. Malaria DNA amplification and serologies for hepatitis $A$ and $B$ were negative.

The patient improved clinically with conservative management. Thrombocytopenia deteriorated slightly to $97 \times 10^{9}$ cells/L and the transaminases increased significantly, both recovering spontaneously on repeat testings.

Repeat dengue groups 1-4 IgG serology was positive after two weeks, consistent with primary dengue infection.

\section{QUESTION 3}

What is the natural history of dengue?

\section{QUESTION 4}

How is the diagnosis of dengue confirmed?

\section{QUESTION 5}

How should dengue be managed in a primary setting?

\section{ANSWER 3}

Dengue infections can be asymptomatic. ${ }^{7}$ In significantly symptomatic patients there is an incubation period of 3-10 days after the bite, followed by one of the two main forms. ${ }^{8}$

Non-severe dengue is self-limiting and characterised by sudden onset high fever usually lasting 5-7 days, with constitutional symptoms and occasional haemorrhagic manifestations.

Severe dengue is less common in Australia as it is associated with repeated infections by different serotypes. ${ }^{6,9}$ It is characterised by abnormal haemostasis 


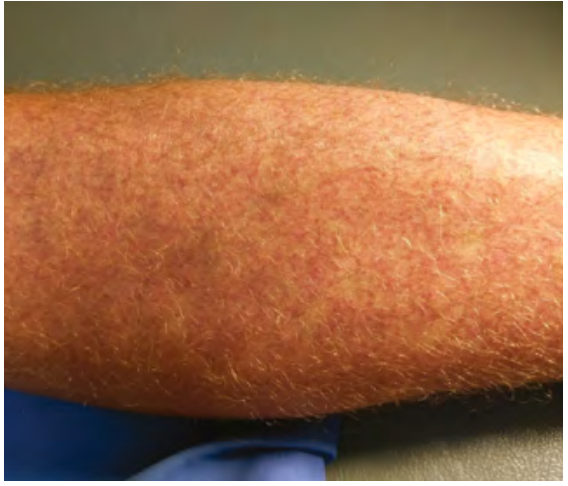

Figure 1. The fine macular rash covering the torso and limbs

and plasma leakage, typically commencing on day 4-5 of illness, after the fever defervesces (Figure 2). Warning signs include severe abdominal pain, persistent vomiting, lethargy or restlessness, hepatomegaly, reduced oral intake, oliguria, postural hypotension and mucosal bleeding. Laboratory findings include increased haematocrit and concurrent rapid decrease in platelet count.

\section{ANSWER 4}

The serum viral RNA polymerase chain reaction (PCR) is sensitive and specific within days 1-5 of symptom onset, after which it becomes negative. Similarly, the NS1 viral antigen is detectable up to day nine. The preferred test may vary between pathology providers.

Dengue IgM is detectable from day six of illness, and IgG from day eight. Cross-reactivity with other viruses such as chikungunya can occur, and paired samples taken 10-14 days apart may be required to confirm IgG seroconversion. ${ }^{9}$

Dates of travel and symptom onset should be clearly noted on the serology request form to aid interpretation. ${ }^{3}$

\section{ANSWER 5}

Prompt notification to the local public health unit is mandated on probable or confirmed diagnosis. ${ }^{10}$ In tropical north Queensland in particular, urgent household and community prevention measures may be required, with patients advised to stay indoors and the household recommended to use insect repellent. ${ }^{3}$

Treatment for dengue is supportive. Patients without clinical warning signs and a near normal blood count can be treated as an outpatient with oral rehydration and paracetamol. Non-steroidal anti-inflammatory medicines are not recommended because of the risk of

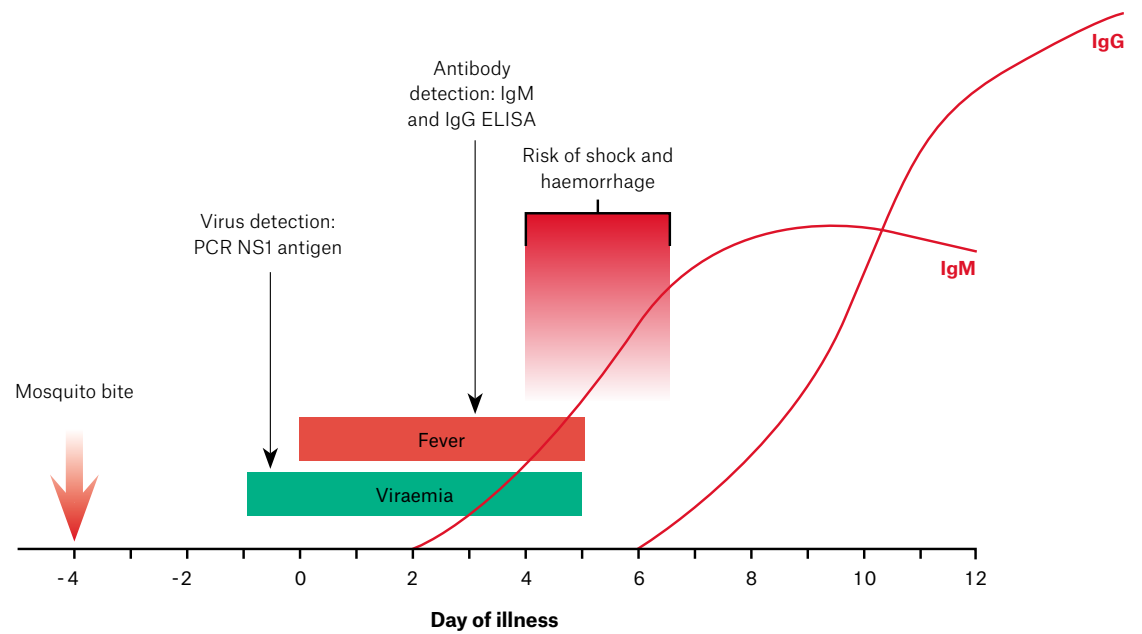

Figure 2. Timing of serology tests and high-risk period in primary dengue Reproduced with permission from Queensland Dengue Management Plan 2015-2020, Queensland Health. ${ }^{9}$ ELISA, enzyme-linked immunosorbent assay; Ig, immunoglobulin; NS1, non-structural protein 1; PCR, polymerase chain reaction increased bleeding. ${ }^{8}$ Patients should be provided with oral and written instructions to attend hospital if the warning signs of severe dengue occur, or symptoms fail to improve during transition to the afebrile phase. Guidelines suggest daily clinical review and blood count until the critical period passes. ${ }^{8,11}$

It is recommended that patients with warning signs or risk factors such as pregnancy, chronic medical conditions and extremities of age be admitted to hospital for observation and consideration of intravenous fluid replacement. ${ }^{8,11}$

\section{Key points}

- Dengue is a common cause of fever and rash in returned travellers from South-East Asia.

- NS1 antigen or PCR assay is valuable early in the course of illness; if negative or baseline IgM is positive, convalescent serology may be useful to confirm IgG seroconversion.

- Management is conservative, with an emphasis on patient education regarding warning signs, close monitoring and public health measures.

- Patients with comorbidities, difficult social circumstances or warning signs for severe dengue should be referred to hospital.

\section{Authors}

Wayne Liao DCH, MBBS, RACGP, General Practitioner, Wellington Point Family Practice, Qld. Wayne103683@gmail.com

Naomi Runnegar MBBS, FRACP, FPCPA, Infectious Diseases Physician and Clinical Microbiologist, Princess Alexandra Hospital, Qld; Senior Lecturer Southern Clinical School, Faculty of Medicine, University of Queensland, Qld

Competing interests: None.

Funding: None.

Provenance and peer review: Not commissioned, externally peer reviewed.

\section{References}

1. Leder K, Torresi J, Libman MD, et al. GeoSentinel surveillance of illness in returned travellers, 2007-2011. Ann Intern Med 2013;158(6):456-68. doi: 10.7326/0003-4819-158-6-20130319000005.

2. Wilson ME. Travellers' health: Fever in returned travellers. Atlanta: Centers for Disease Control and Prevention, 2017. Available at wwwnc. cdc.gov/travel/yellowbook/2018/post-travelevaluation/fever-in-returned-travelers [Accessed 26 April 2019]. 
3. Queensland Health. Dengue. Brisbane: Queensland Health, 2017. Available at www. health.qld.gov.au/clinical-practice/guidelinesprocedures/diseases-infection/diseases/ mosquito-borne/dengue [Accessed 26 April 2019].

4. Knope K, National Arbovirus and Malaria Advisory Committee, Giele C. Increasing notifications of dengue in Australia to overseas travel, 1991 to 2012. Commun Dis Intell Q Rep 2013;37(1):E55-59.

5. World Health Organization Regional Office for the Western Pacific (WPRO-WHO). Dengue situation update number 533. Manila: WPRO-WHO, 2018. Available at www.wpro.who.int/emerging diseases/dengue_biweekly_report_20180102. pdf?ua=1 [Accessed 30 April 2019].

6. Tai AYC, McGuinness SL, Robosa R, et al. Management of dengue in Australian travellers: A retrospective multicentre analysis. Med J Aust 2017;206(7):295-300. doi: 10.5694/mja16.01056.

7. Porter KR, Beckett CG, Kosasih H, et al.

Epidemiology of dengue and dengue hemorrhagic fever in a cohort of adults living in Bandung,

West Java, Indonesia. Am J Trop Med Hyg

2005;72(1):60-66.
8. World Health Organization and the Special Programme for Research and Training in Tropical Diseases (TDR). Dengue guidelines for diagnosis, treatment, prevention and control: New edition. Geneva: WHO, 2009; p. 147.

9. Queensland Health. Queensland dengue management plan 2015-2020. Queensland: Queensland Health, 2015; p. 61.

10. Department of Health. Dengue virus infection case definition. Canberra: DoH, 2017. Available at www.health.gov.au/internet/main/publishing.nsf/ Content/cda-surveil-nndss-casedefs-cd_dengue. htm [Accessed 26 April 2019].

11. Rajapakse S, Rodrigo C, Rajapakse A. Treatment of dengue fever. Infect Drug Resist 2012;5(1):103-12. doi: 10.2147/IDR.S22613. 